\title{
The Effect of Sports Exercises on Students' Differentiation and Perfectionism
}

\author{
Azadeh Safari YAZD ${ }^{1}$, Amin AZIMKHANI ${ }^{*}$ (D), Reza AMINZADEH ${ }^{1(D)}$ \\ ${ }^{1}$ Imam Reza International University of Mashhad, Mashhad, IRAN.
}

Original Article

Received: 18.08.2021
Accepted: 16.12.2021
DOI: $10.25307 /$ jssr.962198

Online Publishing: 31.12.2021

\begin{abstract}
This study aimed to determine the effect of sports exercises on students' differentiation and perfectionism. The present study was applied in terms of purpose and terms of the method used; it was a quasi-experimental study with a pretest-posttest design with a control group. The statistical population includes; female students of the first year of high school who were studied using peer matching between the ages of 13-15. Due to the quasi-experimental nature of the research through G-Power software, 32 students in the experimental group and 15 students in the control group were studied. Data collection was based on Azimkhani, Hejazi \& Aminzadeh's training protocol (2019), as well as the Perfectionism Questionnaire (Hill, Huelsman, Furr, Kibler, Vicente, \& Kennedy, 2004) and the Differentiation Questionnaire (Drake, Murdock, Marszalek, \& Barber, 2015). Based on the findings; Can be observed through dependent t-test and analysis of covariance; In the experimental group in the pre-test and post-test in the variable components of differentiation and perfectionism, the significant levels of the dependent $t$ test are less than 0.05. Therefore, it can be said; significant changes have been made in the variables of differentiation and perfectionism in pre-test and post-test. Conclusion; According to the findings, to increase the psychological and physical factors and the effect of the sports coach, all other factors; Including educational support, the quality of the halls, and educational environments, can be a serious help for students. On the other hand, the type of training along with professional trainers can be a great help for all students, even elite athletes.
\end{abstract}

Keywords: Sports activities, self-concept, perfectionism, self-differentiation

\footnotetext{
* Corresponding Author: Assist. Prof. Amin Azimkhani, E-mail: amin.azimkhani@imamreza.ac.ir, Phone No.: +98915 5104950
} 


\section{INTRODUCTION}

Sport has a suitable position than other educational methods in terms of its effectiveness in developing values and psychosocial growth of individuals. Human life is full of challenging and exciting situations that a person should learn how to confront. The lessons that a person learns from sports help him/her make the appropriate ethical decisions and judgments in life (Lotfi, Mohammadi, Sohrabi, \& Bagherzadeh, 2013).

On the other hand, sports activities have positive and effective effects on physical and mental health, and exercise has been used to treat physical and mental disorders (Asadi, 2011); Therefore, doing sports activities according to the principles of health can also improve the physical and mental health of people during epidemics (Saatchian, Azimkhani, Türkmen \& Laein 2021). In this way, Quested and Duda (2009), Emphasized the positive effects of exercise and physical activity on psychological well-being and quality of life related to health. Researchers have also shown a strong correlation between physical activity and psychological well-being (Huta and Ryan, 2009).

Behavioral disorders include behaviors in children and adolescents that are inappropriate for their age, inconsistent with their cultural status, and do not endorse the ethical conditions of their living environment. This mismatch in behaviors and emotions affects a person's public life, and its symptoms can be seen in sports activities and social life (Azimkhani, Shahrivari, Nategh, \& Azizi Javan, 2010). Inactivity is one of the effective factors in mental-psychical disorders. Research confirms that people with mental illness should be looked for among sedentary people.

Regular exercise is an essential factor in maintaining physical and mental health (Hosseinpour and Kashef, 2012). In this way, in their study, Rao, Noronha and Adiga (2020) concluded that exercise has certainly helped reduce differentiation components, including stress, anxiety, and improve self-esteem and quality of life in patients with depression. Also, Akandere and Tekin (2002), In their research they found; Physical activity and exercise at all ages can reduce anxiety.

On the other hand, Alfermann and Stoll 2000) pointed out that regular participation in sports activities promote self-worth, physical abilities, self-confidence, and reduces psychological stress. The function of physical education and sports is often aimed at providing services such as good leisure, ensuring a healthy lifestyle, and having a social dimension (Griban et al., 2021). The importance of exercise in increasing mental health in individuals has led researchers to examine the effective and psychologically effective variables in exercise. In psychology, it is the starting point of therapy and the promotion of mental health. Hence, psychologists have devoted a large part of their research to their concept. In this regard, Brown et al. (2010) found in their research that their aerobic exercise program effectively improved depression, anxiety, confusion, purposefulness, and extreme fatigue, which was especially effective in girls than boys.

On the other hand, Khajeh Salehani (2007) also shows the effect of sports activities in reducing depression in visually impaired female students. Also, in their research, Mahdavi Nissiani, Ghale noye, Fazeli Farsani, and Hashemi (2016) concluded that exercise was an effective factor 
in promoting psychological well-being, sleep quality, and quality of life of female students, and female student-athletes experienced better sleep quality, psychological well-being, and quality of life than non-athlete students. A similar study, Soltani Shal, Mohammadian Sharabaf, and Ghanaei Chamanabad (2013). in a study entitled "The effectiveness of exercise on the quality of life of Ferdowsi University students" showed that exercise program could significantly reduce anxiety, and physical symptoms, depression, and general health of female students and also increase the quality of life, sleep quality and general health of male students.

What is very important in adolescence is self-differentiation. During this period, the adolescent strives to achieve differentiation. It means that he/she tries to chart her path, not to follow the instructions of family or others constantly, but she/he is often incapable of achieving this goal. Therefore, helping adolescents promotes and increases their differentiation, also helping them to separate reason and emotion seems necessary (Beheshti Roy, 2012). In this way, Ameri and Amooi (2016), in their research, concluded that family performance could be an important and influential factor in the experience of identity crisis and levels of differentiation in adolescence. Olivares, Cossio-Bolaños, Gomez-Campos, Almonacid-Fierro and Garcia-Rubio (2015), in a study, concluded that both parents and physical education teachers were effective in promoting physical activity in adolescents regardless of age, gender, and physical condition, although parents were more influential in that. This means that self-differentiation expresses how a person can distinguish intellectual processes from emotional processes to achieve a degree of emotional independence that the individual is in emotional situations can make decisions rationally and autonomously without being overwhelmed by the emotional atmosphere. However, one of the significant problems that have a deterrent and detrimental effect on the efficiency and dynamism of adolescents and prevents the healthy formation of identity as well as the flourishing of talents and intellectual and emotional powers in them is the problem of low discrimination in children and adolescents Is. According to research, differentiation is a fundamental feature for adolescents, and adolescents with lower levels of differentiation usually experience higher levels of anxiety and have more impaired cognitive function. Considering that low differentiation can have detrimental and inhibitory effects on establishing healthy social relationships and expressing feelings and thoughts, so addressing this important issue is essential (Hadidi, Zare Bahramabadi, \& Shafiabadi, 2010). In this way Zoghi, Torabian and Ajilchi's research (2019) have shown that highly differentiated people experience less social anxiety. Also, in his research, Mohammadpour (2019) found that young people, who are involved in sports activities, achieve a more independent and real individual identity during these social activities. This individual independence that by generalizing to the whole of life as a way of life, can increase self-differentiation and less integration with others.

Today, young people who exercise show a high level of self-esteem, emotional acceptance, ability to solve problems, achieve goals, and social abilities compared to young people who do not regularly exercise (Pulido, Borràs Rotger, Salom, Ponseti, \& Verdaguer, 2018). In this way, Andrews and Armstrong-Soule (2017) believe that people, who participate in various physical activities, including games and sports, are more differentiated from others throughout their lives. Also, Curran (2012) also considers participation in sports activities to increase selfconfidence and greater life satisfaction. Chard et al., (2020) found in their study that adolescent girls experience high levels of body dissatisfaction and low self-esteem, as well as low levels of participation in physical activity. Furthermore; Outside of traditional sports, there are few 
recreational opportunities to promote physical, emotional, and mental well-being in adolescent girls.

In addition to its differentiation, perfectionism is an important aspect of mental health during adolescence, which reaches maturity and maturity (Damian, Stoeber, Negru, \& Băban, 2013), and adolescence is mentioned as a stage that is of particular importance due to the formation of the perception of well-being and its transfer to the following stages of development (Codina and Pestana, 2016), and (González, Garcés de los Fayos and García Del Castillo, 2011). Perfectionism is an accurate and sensitive assessment based on which people expect to do their job with excellent performance, standardization, and success (Frost, Maten, Lahar, \& Rosenblate, 1990). According to Burns (1980), perfectionists have a dual evaluation of their experiences based on "all or nothing", which divides their way of thinking into positive and negative poles (Shajee, Koozehchian, Amiri, \& Eghbali Hashtjin, 2011). Due to the value and reciprocity of perfectionism, this variable can be both a contributing factor in achieving the goal and an obstacle to achieving success and great goals in athletes. Perfectionism depends on the situation in which a person is, and people's attitudes toward these conditions can be both positive and normal and lead to success, satisfaction, and achievement of the chosen and have a negative and abnormal aspect and cause dissatisfaction, disappointment, and psychological damage (Hamachek, 1978). In this regard, the results of Sufiani's research (2007) confirm that perfectionism is one of the most common characteristics among adolescents and leads to high anxiety and negative mood in the educational environment. Also, Studies by Choy and McInerney (2007) showed that perfectionist students experience negative emotions and psychological distress before, after, and even while performing the tasks being evaluated. Fear of negative evaluation by others causes them to have high anxiety while doing their work. In return, Andam, Kharkan and Mehdizadeh (2013), in their research, concluded that perfectionism cannot always be considered as a negative factor in predicting aggression; Because normal perfectionism reduces aggression; Therefore, the normal and abnormal dimensions of perfectionism must be considered simultaneously. Also, Besharat (2005) showed a simple positive and negative correlation between positive and negative perfectionism with sports success, respectively, but only positive perfectionism can significantly predict changes related to sports success.

On the other hand, results of Sarv's research (2008); affirm that positive perfectionism, directly and indirectly, Students' academic achievement has a positive effect, and test anxiety has a mediating role concerning negative perfectionism and academic success. Also, Stumpf and Parker (2000) stated in a study that there is a relationship between negative perfectionism and neuroticism; it has to do with perfectionism because neurotic people are worried about making mistakes and have doubts about what they are doing. They also showed a significant relationship between positive perfectionism and conscientiousness because they found a relationship between conscientiousness and personal standards.

Athletes' perfectionism is largely a healthy structure. In this kind of perfectionism, rational mechanisms are active. In this mechanism, the focus shifts from hostility and anger to stubbornness and perseverance; Hence, athletes pay less attention to its worrying aspects to succeed in sports (Andrews, Singh and Bond, 2004). In this way (in their study, Hernandez and Villena, 2019) concluded that indicators of perfectionism increase the intensity of physical activity, regulate stress, and reduce psychological factors such as anxiety and stress. Although 
in the field of sports psychology, this structure is doubly important due to its direct effect on sports performance and success (Byrd, 2011), But Adjusting perfectionism helps the athlete to be less affected by competitive anxiety and increase self-confidence, thus increasing the likelihood of success (Arbab, Vaez Moosavi, \& Badami, 2016). In this way, Mousavi, Vaez Mousavi and Yaghoubi (2015), in their research, concluded that the need to maintain the desired level of sports perfectionism to achieve the peak performance of athletes is appropriate. Also, in their research, Ahrari, Azimkhani, and Keshtidar (2018) concluded that students participating in sports leisure classes that have a spirit of perfectionism and assertiveness are more successful in sports. On the other hand, Springer, Appleton and Hill (2012) concluded that perfectionism reduces athlete burnout by increasing motivation in athletes. Due to the lack of research on the variables of differentiation and perfectionism and its necessity in semiexperimental students, also due to the fact that students are the future makers of society, the importance of this research has doubled. Due to this necessity, the purpose of this study is the effect of exercise on students' differentiation and perfectionism.

\section{METHOD}

\section{Research Model}

The present study is applied in terms of purpose and terms of the method used is a quasiexperimental study with a pre-test-post-test design with a control group. In this plan, both experimental and control groups were assessed simultaneously in the pre-test stage, then the experimental group performed the exercise, and during this period, the control group did not receive the exercise. Both experimental and control groups were assessed again in the post-test phase, at the end of the training period.

\section{Participants}

The statistical population of this study consists of female high school students (13-15 years old) in Mashhad. Due to the quasi-experimental nature of the study, 32 students in the experimental group and 15 students in the control group were studied. The matching of the study groups was selected based on the age range of adolescents aged 13-13 years; then, they were studied by random substitution. The experimental group performed their activities for 24 sessions of 90 minutes, three sessions per week, for two months, including physical training and specialized volleyball training. It should be noted that subjects were selected to participate in the study who were in perfect physical and mental health and had not been treated with medication; none of the subjects had previous experience in homework and were not aware of the study's objectives.

\section{Instrumentation and Methods of Data Collection}

In this research, after preparing the desired questionnaires, the necessary coordination regarding the research was done among the study population, and the research questionnaires were distributed and collected.

After that, sports exercises were performed among the experimental group, and at the end, the research questionnaire was redistributed and collected and analyzed by appropriate statistical tests, and the research report was prepared. The data collection instrumentation required for the research included the following questionnaires: 
Perfectionism Questionnaire (Hill et al., 2004); includes 64 questions and eight components (focus on mistakes (questions 1 to 8 questionnaires), high criteria for others (questions 9 to 15 questionnaires), the need for approval (questions 16 to 23 questionnaires), order and organization (questions 24 to 31 questionnaires), pressure perception by parents (questions 32 to 39 questionnaires), Purposefulness (questions 40 to 46 of the questionnaire), rumination (questions 47 to 53 of the questionnaire) and striving for excellence (questions 54 to 59 of the questionnaire) are scored in a five-choice Likert scale, strongly disagree (score 1) to strongly agree (score 5). In this way, in each article, they must first give a "strongly disagree" answer number 1, "disagree" with score 2, "neither agree nor disagree" with score 3, "agree" with score 4, and "strongly agree" with score 5. In the study of Jamshidi, Hossein Chari, Haghighat, and Razmi (2009), the reliability of this questionnaire was evaluated using Cronbach's alpha coefficient method, and its convergent validity was evaluated by examining the relationship between the dimensions of the scale and the general health scale. The calculation of Cronbach's alpha coefficient showed acceptable reliability of 0.80 of this questionnaire. The scale's validity was also confirmed despite the relationship between the negative dimensions of perfectionism and mental health. In Iran, a study conducted by Khalatbari, Ghorban Shiroodi and Hosseini (2011), the reliability of the whole scale in the preliminary study (68 subjects) using Cronbach's alpha method (internal synchronization) was 0.80 . In the main study with (313 subjects) after factor analysis, this coefficient was obtained for the whole scale of 0.90 .

Self-Differentiation Questionnaire - Short; Form Drake et al. (2015) (DSI-SF), including 20 questions and five components of non-approval (questions 1 to 6 of the questionnaire), stress and emotional instability (questions 7 to 11 of the questionnaire), fusion Thought and Action (Questions 12 to 16 of the Questionnaire), Avoidance (Questions 17 to 18 of the Questionnaire), Criticism (Questions 19 to 20 of the Questionnaire) are scored on a five-point Likert scale: strongly disagree (score 1) to strongly agree (score 5). In this way, in each article, they must first give a completely negative answer number 1 , disagree with score 2 , neither agree nor disagree with score 3 , agree with score 4, and strongly agree with score 5. In Rasooli, Asoudeh, Tamarchi and Hosseini's research (2016), the results showed that the structure of the questionnaire has an acceptable internal consistency. In this study, after examining the content validity, Cronbach's alpha coefficient was used to evaluate the reliability of the questionnaire, and Cronbach's alpha coefficients for the whole questionnaire were 0.74. Also, the results of principal component analysis using varimax rotation led to the extraction of five factors. The results of factor analysis confirm that the structure of the questionnaire has an acceptable fit with the data and the suitability of confirmatory factor analysis based on SPSS software confirmed the existence of five factors. The confirmatory factor analysis results confirm that the structure of the questionnaire has an acceptable fit with the data, and all indicators of good fit confirm the model.

\section{Procedure}

First, a list of all schools in Mashhad was prepared to select the sample, and then among them was selected using the purposive sampling method of Shahid Motahari School. In this school, out of 144 adolescents aged 13-15, 70 female adolescents were selected based on the opinion of the school clinical psychologist and also based on the tests taken from them, of which 23 were not willing to cooperate for research; As a result, 47 people were selected as the sample. Of these, 32 were in the experimental group using G-power software, and 15 were in the control 
group. The experimental group practiced for 3 minutes during eight weeks, and each session lasted for 90 minutes, and the control group was engaged in normal sports activities at school during the study. Practical interventions were performed based on the training protocol of Azimkhani et al. (2019). In this research; During 24 sessions, for each session, the subjects performed warm-up activities (stretching, flexibility, jogging) for 10 minutes, and 40 minutes, performed physical and motor fitness exercises to assess cardiorespiratory endurance (12minute running test). Anaerobic power (vertical jump or sergeant), speed (36 meters or 40 yards), agility ( $4 \times 9 \mathrm{~m}$ test), muscular endurance (sitting), and power (longitudinal jump) with an intensity of $80-85 \%$ of maximum heart rate with the use of the polar machine was addressed. Then, for 30 minutes, they practiced specialized volleyball exercises (moving on the ground, paw pass, forearm pass, service, spike, etc.). At the end of each training session, the subjects participated in cooling activities for 10 minutes. These exercises include:

\section{0 meters running}

The distance of 540 meters on the appropriate surface is determined at the beginning and end. This distance is used as the start and end lines. The volunteer is placed behind the starting line and travels 540 meters with the start command.

\section{Explosive Power of Legs by Vertical Jump Test}

The student dips his fingertips in plaster and stands $15 \mathrm{~cm}$ from the wall with the shoulder of the upper hand (right or left) facing the wall; Mark the highest point on the wall by raising and pulling the hand. Then she jumps up with a jump and marks the highest point on the wall with her fingertips. The distance between these two marks determines the amount of vertical jump or the student's record in this test, which indicates the student's muscular strength.

\section{6-meter sprint test (40 yards)}

At the starting line, the student should be ready to move with the knees bent and start running at maximum speed towards the end of the track with the start command. After the student crosses the finish line, the time indicated by the timer is recorded.

\section{$4 \times 9$ meters running}

The student stands behind the starting line and starts running with the start command. After reaching the end of the path, he picks up one of the sticks, returns to the starting line and places it on the ground behind the line, and does the same for the second time; but in return, there is no need to put the second stick on the ground, and it crosses the line at the same speed. The time between the start and the end is recorded in a few seconds.

\section{Sit-ups}

The athlete lies on his back, bends his knees, and places the soles of his feet on the ground. He crosses his arms over his chest, his left hand on his right shoulder and his right hand on his left shoulder. He squeezes his abdomen, then lifts his head, shoulders, and chest to his knees, leaving only his seat and the soles of his feet on the floor. It then starts with the word start, which coincides with pressing the stopwatch button. This movement is performed in one minute and is recorded as a measuring scale. 


\section{Jump lengths in place}

Draw a line on the ground, and the student is placed behind it. He must jump forward as long as he can. The location of the heel landing up to the drawn line determines the amount of jump. At the same time, the control group was prevented from doing any sports activities and participated only in pre-test and post-test (Azimkhani et al., 2019).

\section{Data Processing Methods}

Data analysis in the present study was performed in two parts: descriptive and inferential. Thus, in the descriptive statistics section, descriptive statistics of research variables, including mean and standard deviation, were described, and then for analysis of inferential research data, analysis of covariance and dependent t-test for paired samples were used. It should be noted that all statistical analyzes were performed using SPSS software version 21.

\section{FINDINGS}

The results of descriptive information in two groups (one experimental group and one control group) show that the experimental group is $53.1 \%$ aged 12 to 13 years and $46.9 \%$ are aged 14 to 15 years, and in the experimental group, $80 \%$ are 12 to 13 years old. Years and $20 \%$ are 14 to 15 years old. $28.1 \%$ are seventh grade in the experimental group, $25 \%$ are eighth grade, and $46.9 \%$ are ninth grade. Also, $26.7 \%$ are seventh grade in the control group, $46.7 \%$ are eighth grade, and $26.7 \%$ are ninth grade. $59.4 \%$ of fathers are self-employed in the control group, and $40.6 \%$ are employed, while in the control group, $33.3 \%, 60 \%$ are employed, and one person is equivalent to $6.7 \%$. In the experimental group, $81.3 \%$ are housewives, $15.6 \%$ are employees, and $3.1 \%$ are equivalent to one person, $93.3 \%$ are housewives in the control group, and $6.7 \%$ are equivalent to one employee. In the experimental group, $6.5 \%$ of fathers have a sub-diploma, $32.3 \%$ have a diploma, $22.6 \%$ have a bachelor's degree, and $38.7 \%$ have a master's degree. Also, $13.3 \%$ have a diploma in the control group, and $33.3 \%$ have a bachelor's degree. Moreover, $53.3 \%$ have a master's degree. In the experimental group, $6.5 \%$ of fathers have an undergraduate degree, $32.3 \%$ have a diploma, $22.6 \%$ have a bachelor's degree, and $38.7 \%$ have a master's degree. Also, $13.3 \%$ have a diploma in the control group, and $33.3 \%$ have a bachelor's degree. Moreover, 53.3\% have a master's degree. In the following, we will provide descriptive information about the research variables in the two measurement times, namely pre-test and post-test.

Table 1. Descriptive indices of variable components of differentiation in the control group in pre-test and post-test

\begin{tabular}{lcccc}
\hline & Pre-test & \multicolumn{2}{c}{ Post-test } \\
\hline & Average & Std.Dev. & Average & Std.Dev. \\
\hline Not approved & 2.27 & 0.71 & 2.15 & 0.54 \\
Stress and Emotional Instability & 2.85 & 0.70 & 2.47 & 0.45 \\
A Fusion of Thought and Action & 3.22 & 0.94 & 3.93 & 0.72 \\
Avoid & 2.03 & 1.26 & 1.62 & 0.65 \\
Criticism & 2.00 & 1.00 & 1.61 & 0.52 \\
\hline
\end{tabular}

Table 1 shows the descriptive results obtained from the control group on the differentiation variable in both pre-test and post-test modes. The component of thought and action has the highest mean in the pre-test (3.53) and post-test (3.52). 
Table 2. Descriptive indices of variable components of differentiation in the experimental group in pre-test and post-test

\begin{tabular}{lcccc}
\hline & \multicolumn{2}{c}{ Pre-test } & \multicolumn{2}{c}{ Post-test } \\
\hline & Average & Std.Dev. & Average & Std.Dev. \\
\hline Not approved & 2.55 & 0.82 & 2.54 & 0.8 \\
Stress and Emotional Instability & 2.69 & 0.60 & 2.68 & 0.59 \\
A Fusion of Thought and Action & 3.53 & 0.95 & 3.52 & 0.92 \\
Avoid & 2.06 & 1.26 & 2.08 & 1.28 \\
Criticism & 1.93 & 0.75 & 1.92 & 0.75 \\
\hline
\end{tabular}

Table 2 shows the descriptive results obtained from the experimental group about the variable of differentiation in both pre-test and post-test modes. The component of thought and action has the highest mean in the pre-test (3.22) and post-test (3.93).

Table 3. Descriptive indicators of the variables of perfectionism in the control group before and after the test

\begin{tabular}{lcccc}
\hline & \multicolumn{2}{c}{ Pre-test } & \multicolumn{2}{c}{ Post-test } \\
\hline & Average & Std.Dev. & Average & Std.Dev. \\
\hline Focus on Mistakes & 3.38 & 0.73 & 3.39 & 0.72 \\
High Standards for Others & 3.24 & 0.74 & 3.25 & 0.76 \\
Requires Approval & 2.83 & 0.7 & 2.85 & 0.68 \\
Order and Organization & 2.86 & 0.72 & 2.85 & 0.71 \\
Perception of Pressure from Parents & 2.65 & 0.43 & 2.66 & 0.42 \\
Rumination & 2.60 & 0.85 & 2.61 & 0.85 \\
Strive to be great & 2.11 & 0.61 & 2.08 & 0.54 \\
\hline
\end{tabular}

Table 3 shows the descriptive results obtained from the control group on the perfectionism variables in both pre-test and post-test modes. The component focusing on errors has the highest mean in the pre-test (3.38) and post-test (3.39).

Table 4. Descriptive indicators of the variables of perfectionism in the experimental group before and after the test

\begin{tabular}{lcccc}
\hline & \multicolumn{2}{c}{ Pre-test } & \multicolumn{2}{c}{ Post-test } \\
\hline & Average & Std.Dev. & Average & Std.Dev. \\
\hline Focus on Mistakes & 3.24 & 0.79 & 2.66 & 0.54 \\
High Standards for Others & 3.23 & 0.64 & 2.60 & 0.47 \\
Requires Approval & 2.91 & 0.66 & 2.39 & 0.43 \\
Order and Organization & 2.65 & 0.79 & 3.42 & 0.58 \\
Perception of Pressure from Parents & 2.70 & 0.56 & 2.11 & 0.33 \\
Rumination & 2.58 & 0.73 & 2.10 & 0.45 \\
Strive to be great & 2.07 & 0.64 & 2.81 & 0.62 \\
\hline
\end{tabular}

Table 4 shows the descriptive results obtained from the experimental group on the variables of perfectionism in both pre-test and post-test modes. Focusing on errors has the highest average in the pre-test (3.24) and the component of order and organization in the post-test (3.42).

Also, in this analysis, the effect of time, which in this research is the application of an independent variable, i.e., sports classes during sports activities, is examined, and in this regard, the pre-test is controlled as a variable affecting the final result. However, to test this hypothesis, first the dependent t-test and then the analysis of covariance is used. Thus, first, the dependent $\mathrm{t}$-test is presented in the pre-test and post-test. 
Table 5. Dependent t-test in the experimental group in pre-test and post-test in differencing components

\begin{tabular}{lcccc}
\hline Indicators & $\mathbf{t}$ & $\begin{array}{c}\text { Degrees of } \\
\text { Freedom }\end{array}$ & $\begin{array}{c}\text { Difference in } \\
\text { Averages }\end{array}$ & $\begin{array}{c}\text { Significant } \\
\text { level }\end{array}$ \\
\hline Not Approved & -2.29 & 31 & -0.12 & 0.007 \\
Stress and Emotional Instability & -5.63 & 31 & -0.37 & 0.001 \\
A Fusion of Thought and Action & 11.34 & 31 & 0.71 & 0.001 \\
Avoid & -3.15 & 31 & -0.40 & 0.004 \\
Criticism & -3.43 & 31 & -0.38 & 0.002 \\
\hline
\end{tabular}

Table 6. Dependent t-test in the experimental group in pre-test and post-test in the variables of perfectionism

\begin{tabular}{lcccc}
\hline \multicolumn{1}{c}{ Indicators } & $\mathbf{t}$ & $\begin{array}{c}\text { Degrees of } \\
\text { Freedom }\end{array}$ & $\begin{array}{c}\text { Difference } \\
\text { in Averages }\end{array}$ & $\begin{array}{c}\text { Significant } \\
\text { level }\end{array}$ \\
\hline Focus on Mistakes & -8.60 & 31 & -0.579 & 0.001 \\
High Standards for Others & -8.58 & 31 & -0.628 & 0.001 \\
Requires Approval & -8.01 & 31 & -0.519 & 0.001 \\
Order and Organization & 11.81 & 31 & 0.767 & 0.001 \\
Perception of Pressure from Parents & -10.06 & 31 & -0.595 & 0.001 \\
Purposefulness & 14.01 & 31 & 0.734 & 0.001 \\
Rumination & -6.73 & 31 & -0.476 & 0.001 \\
Strive to be Great & 12.11 & 31 & 0.743 & 0.001 \\
\hline
\end{tabular}

Table 5 and Table 6; The results show that in the experimental group in pre-test and post-test in the variables of differentiation and perfectionism, the significant levels of the dependent $t$ test are less than 0.05 . Therefore, it is concluded that significant changes have been made in the variables of differentiation in pre-test and post-test.

Table 7. Homogeneity Test of Variances between experimental and control group in the components of throughout fusion

\begin{tabular}{cccc}
\hline F & $\begin{array}{c}\text { Degree of Facial } \\
\text { Freedom }\end{array}$ & $\begin{array}{c}\text { Degree of } \\
\text { Denominator Freedom }\end{array}$ & $\begin{array}{c}\text { The Significance } \\
\text { levels }\end{array}$ \\
\hline 2.28 & 1 & 45 & 0.137 \\
\hline
\end{tabular}

The result indicates that the variance between the two groups has the necessary homogeneity. Therefore, an analysis of covariance can be used.

Table 8. Analysis of covariance of the component of thought and action

\begin{tabular}{cccccc}
\hline Source of Changes & $\begin{array}{c}\text { Total } \\
\text { Squares }\end{array}$ & $\begin{array}{c}\text { Degrees of } \\
\text { Freedom }\end{array}$ & $\begin{array}{c}\text { Average } \\
\text { Squares }\end{array}$ & F & $\begin{array}{c}\text { The Significance } \\
\text { levels }\end{array}$ \\
\hline Modified Model & 28.83 & 2.00 & 13.91 & 248.85 & 0.001 \\
Pre-test Effect & 26.04 & 1.00 & 26.04 & 465.64 & 0.001 \\
Group Effect & 4.43 & 1.00 & 4.43 & 79.33 & 0.001 \\
Error & 710.87 & 44 & 0.056 & - & - \\
\hline Total & 30.29 & 47 & - & - & - \\
\hline
\end{tabular}

The level of significance related to the group factor is less than 0.05 . Therefore, it can be said that sports activities have an increasing effect on the component of thought and action. If the $\mathrm{F}$ value of the covariate is not significant, the results of the analysis of covariance are correct for comparing the groups, but the selected covariate has no effect on the proposed model; Therefore, it can be said that the controlled variable, which is the amount of pre-test is a 
component of the fusion of thought and action, affects the amount of post-test that this effect is controlled.

Table 9. Homogeneity Test of Variance between Experimental and Control Groups in the Component of Focusing on Errors

\begin{tabular}{cccc}
\hline F & $\begin{array}{c}\text { Degree of Facial } \\
\text { Freedom }\end{array}$ & $\begin{array}{c}\text { Degree of } \\
\text { Denominator } \\
\text { Freedom }\end{array}$ & $\begin{array}{c}\text { The Significance } \\
\text { levels }\end{array}$ \\
\hline $0 / 588$ & 1 & 45 & $0 / 455$ \\
\hline
\end{tabular}

The result indicates that the variance between the two groups has the necessary homogeneity. Therefore, an analysis of covariance can be used.

Table 10. Analysis of covariance component of focus on errors

\begin{tabular}{cccccc}
\hline Source of Changes & $\begin{array}{c}\text { Total } \\
\text { Squares }\end{array}$ & $\begin{array}{c}\text { Degrees of } \\
\text { Freedom }\end{array}$ & $\begin{array}{c}\text { Average } \\
\text { Squares }\end{array}$ & F & $\begin{array}{c}\text { The Significance } \\
\text { levels }\end{array}$ \\
\hline Modified Model & 19.56 & 2.00 & 9.78 & 177.31 & 0.001 \\
Pre-test Effect & 14.14 & 1.00 & 14.14 & 256.40 & 0.001 \\
Group Effect & 3.98 & 1.00 & 3.98 & 72.18 & 0.001 \\
Error & 2.42 & 44 & 0.055 & - & - \\
\hline Total & 415.98 & 47 & - & - & - \\
\hline
\end{tabular}

According to Tables 7, 8, 9, 10 in the experimental group in pre-test and post-test in the variables of differentiation and perfectionism, the significant levels of analysis of covariance are less than 0.05 .

\section{DISCUSSION}

This study aimed to investigate the effect of sports activities with a psychological approach on students' differentiation and perfectionism. The findings showed; Eight weeks of exercise has a significant effect on the variable components of students' differentiation. Due to the natural distribution of variables and the fact that they were of the distance type, dependent t-test, and analysis of covariance were used to test the relevant hypothesis. The results showed a significant difference between pre-test and post-test in all dimensions of differentiation in the experimental group.

Furthermore, analysis of covariance showed that the post-test effect on the post-test was also significant, which was also controlled. This result is consistent with the results of research by Sahafi and Piri (2020), and Salesi, Shakur, Pouranfar, Koushki Jahromi and Roozbeh (2014), Smith and Elliott (2017). Also, Mohammadpour (2019), in his study entitled "Comparison of the degree of differentiation in female athletes and non-athletes", concluded that the degree of differentiation in the two groups of athletes and non-athletes is significantly different.

One of the psycho-developmental variables that can affect exercise is its differentiation. Differentiation refers to the ability to balance intellectual and emotional processes at the intrapsychological level and to balance individuality with the experience of intimacy at the interpersonal level (Tuason and Friedlander, 2000). Its differentiation can be examined at two levels; at the interpersonal level, differentiation or integration occurs when people do not separate their emotions from their thinking and instead drown in emotion. At the interpersonal 
level, the undifferentiated person tends to either be completely absorbed in the feelings of others and move with the emotional atmosphere of the environment or react the opposite against others (Sohrabi, Asadi, Habibollahzade and PanaAli, 2013). The results also showed that exercise had a significant reduction effect on the non-approval dimension.

The results also showed that exercise had a significant reduction effect on the non-approval dimension. The non-approval dimension examines the importance of being approved or not approved by others and its impact on people's behavior. Exercise can reduce the importance of approval or disapproval by others in students; students feel less dependent on being approved by others with eight weeks of exercise. Exercise and physical activity, given that it gives a person a sense of confidence and usefulness, therefore; People are not afraid of being approved by others; this means that exercise can develop self-approval through inner senses, thus reducing the need for approval from others. Perhaps one factor in confirming dependence on students' approval before exercise was one-dimensional dependence on family and participation in social activities, given that students experience different types of emotions through exercise and group communication in sports activities. Perhaps, one factor is not important to confirm the same factors mentioned. On the other hand, the presence of a clinical psychologist along with a sports coach and emotional interactions can be another factor that the student does not react to dependence factors.

Another dimension of differentiation that showed a significant reduction in physical activity was students' stress and emotional instability. To explain this result, it can be stated that increasing the level of serotonin and norepinephrine during exercise reduces stress levels as well as depression. In other words, exercise can affect the body in two ways: 1. by releasing endorphins 2. Reducing cortisol levels (Smith and Elliott, 2017).

On the other hand, exercise depletes energy and thus, relaxes people, which is also due to the secretion of endorphin hormones. Therefore, on the one hand, exercise seems to help the body get more endorphins and serotonin, and on the other hand, it is maintained for a longer period in the exercise process. Due to the above and the secretion of the hormone serotonin, which reduces depression, in this study, perhaps one of the influential factors can be considered the principles of exercise, including the principle of overload, individual differences, and the principle of characteristics of exercise in these activities. Another dimension was the differentiation of thought and action. The results showed that exercise could improve the fusion of thought and action. Because sport is a group and social activity, and naturally, self-sacrifice and forgiveness can be seen in it. Collaboration between people affects their emotions, and thus the student reaches social maturity, which is the goal of the research.

Another component was the differentiation of avoidance. This concept means how much people distance themselves from other people and avoid communication. The results showed that exercise could reduce avoidance. The reason for this, which has been discussed before, is the group nature and social nature of sports. In sports, students learn that communication must exist. Especially in this research, in addition to physical fitness exercises, specialized volleyball exercises were performed. Group sports have a positive effect on socialization (Pourshahabadi, 2015). However, it can be said that group sports activities need to be communicated and, in this regard, can reduce the avoidance or distance of people from each other. 
Another component was the differentiation of the sense of criticism. The results showed that exercise could reduce students' sense of resentment over criticism. As mentioned in the previous sections, sports and especially sports used as an independent variable in this study, i.e., volleyball, are group sports, and naturally, the relationship between people will increase, and there will be criticisms about each other's play. However, criticism does not evoke a sense of hatred because it is in line with a goal, i.e., the conclusion of the team, students try to work to help the team, therefore their sense of criticism is strengthened, and they become upset. Criticism is reduced in them.

Also, exercise had a significant effect on the variable components of students' perfectionism. The results showed that in the experimental group in the pre-test and post-test in the perfectionism variables, the significant levels of dependent t-test and analysis of covariance are less than 0.05. Therefore, it is concluded that significant changes have been made in the variables of perfectionism in pre-test and post-test. This result is consistent with the findings of Entezari, Shamsi Pourdehkordi and Sahaf (2017), Nerland and Sæther (2016), Khalatbari et al. (2011), and Stober and Domain (2014). Perfectionism is a behavioral trait in which a person is interested in improving his performance (Elliot, 1999). Physical activity for perfectionists can reduce stress and rumination in them and lead people to excel. Therefore, it can be said; the more they have a sporty lifestyle, the higher the level of their cognitive factors is positively evaluated. Another thing that can improve perfectionism is the effect that the physical image of sports activities has on individuals (Bakhshi Soureshjani, 2015). Students' appropriate body image can lead them to perfection and strengthen their striving for excellence. The exercises used as an independent variable in this study, i.e., physical fitness exercises and specialized volleyball exercises, were to the extent that the students had a positive and pleasant experience. As a result, they strengthened their efforts to excel.

Exercise improves students' belief in order; given that, it has certain rules and regulations that must be acted upon within those rules. Also, when students play volleyball, they have to organize. That is, they give each other roles and divide tasks based on their abilities. As a result, students learn that to achieve the goal and be superior, they must maintain order and be well organized.

The need for approval in students in the pre-test has shown a significant reduction; this is because students no longer need to be approved by others when they engage in sports training, and the level of training is commensurate with their skill level because they feel comfortable with approval. Therefore, the need for approval from others diminishes in them. The same is true of parents' perception of pressure. In fact, with exercise, students could relieve parental pressure; this does not mean that parents may put less pressure on students, but it does mean that the student himself feels that he is on the right path and feels superior. As a result, they feel less of a sense of pressure or pressure from their parents. Therefore, it can be said that sports exercises in which students work in groups can reduce the perception of parental pressure on students and thus prepare the student to achieve excellent and perfect conditions. According to the results of this study and the study of other studies, it can be concluded that exercises and group games can help students in differentiation and perfectionism. Furthermore, exercise can reduce negative feelings such as stress and pressure from others and help them achieve higher-level activities. 
Conflicts of Interest: The authors declare that they have no conflict of interest.

Author Contributions: All three authors have made a substantial and intellectual contribution to the study and approved it for publication.

\section{Information on Ethics Committee Permission}

Ethics Committee: 5550

Date: $2 / 12 / 2020$

Decision / Protocol number: 63

\section{REFERENCES}

Ahrari, R., Azimkhani, A. \& Keshtidar, M. (2018). Predicting sports success based on perfectionism and assertiveness in students participating in sports leisure. Master Thesis in Sports Management. Imam Reza International University, Mashhad, Iran.

Akandere, M. \& Tekin, A. (2002). The effect of physical exercise on anxity. Sport journal, 5(2), 150-168.

Ameri, F., \& Amooi, N. (2016). The Role of Family Functioning in the Extent of Experienced Identity Crisis and Differentiation Levels of Adolescents. Journal of Family and Research. 13(30), 77-91.

Andam, R., Kharkan, M. \& Mehdizadeh, R. (2013). The Relationship between Perfectionism and Aggression among Athletic Students, Sports Psychology Studies, 67-84.

Andrews, G., Singh, M., \& Bond, M. (2004). The Defense Style Questionnaire. Journal of Nervosa and Mental Disease, 12, 246-250.

Andrews, S. J., \& Armstrong-Soule, C. (2017). The Influence of regular sports participation on consumer psychology. In The Customer is not always right? Marketing orientationsin in a dynamic business world (pp. 209-211). Cham: Springer.

Arbab, B., Vaez Moosavi, M. K. \& Badami, R. (2016). The relation between sports perfectionism and competitive anxiety in women's national karate team. Research in Sport Management and Motor Behavior, 5(10), 27-35.

Asadi, P. (2011). The effect of morning exercise on psychological skills of non-athlete female high school students in public schools in Ilam province. Master Thesis in Physical Education, Payame Noor University.

Azimkhani, A., Shahrivari, K., Nategh, E. \& Azizi Javan, H. A. (2010). Construction and standardization of Behavioral Disorder Rating Scale in fifth grade elementary students in Tehran (teachers form). Principles of Mental Health, 12, 83-574.

Azimkhani, A., Hejazi, K. \& Aminzadeh, R. (2019). The effect of combined exercise (interval and polymetric) on some physical fitness parameters in middle age Men. Journal of sport sciences Researches, 4(1), 19.

Bakhshi Soureshjani, L. (2015). Survey of perfectionism relationship with depression and bodily image and two latest variations of socio-economic situation in Islamic Azad University Behbahan Branch. Cultural Bulletin, 19(5), 37-60.

Beheshti Roy, N. (2012). The Relationship between parenting styles and self-concept and differentiation of high school students in Yasouj.Master Thesis. Islamic Azad University, Marvdasht Branch.

Besharat, M. A. (2005). A Study of the relationship between perfectionism and sports success. Harakat Magazine, 23(417), 51-65. 
Yazd, A.S. Azimkhani, A. \& Aminzadeh, R. (2021). The Effect of sports exercises on students' differentiation and perfectionism. Journal of Sport Sciences Researches, 6(2), 504-520.

Brown, R. A., Abrantes, A. M., Read, J. P., Marcus, B. H., Jakicic, J., Strong, D. R., ... \& Gordon, A. A. (2010). A pilot study of aerobic exercise as an adjunctive treatment for drug dependence. Mental health and physical activity, 3(1), 27-34.

Burns, D. D. (1980). The perfectionist's script for self-defeat. Psychology today, 14(6), 34-52.

Byrd, M. (2011). Perfectionism hurts: Examining the relationship between perfectionism, anger, anxiety, and sport aggression. Master Thesis. Miami University, Miami, United State of America.

Chard, C. A., Nelson, D. S., Walters, K. A., Pollard, N., Pollard, N., Pollard, N., ... \& Fields, M. J. (2020). An Inclusive approach to exploring perceptions of body 1mage, self-esteem, and physical activity among black and African-American girls: Smart fit girls melanin magic. Journal of Park \& Recreation Administration, 38(3), 21-32. https://doi.org/10.18666/JPRA-2019-9710

Choy, G. \& McInerney, V. (2007). Multidimensions of perfectionism and self concept in school aged children. Paper presented at Australian international education conference, School of Psychology, Self-Research Centre, University of Western Sydney, Australia.

Codina, N. \& Pestana, J. V. (2016). Actividad físico-deportiva como experiencia de ocio y Perspectiva Temporal en los jóvenes. Revista de Psicolo- gía del Deporte, 25(2), 53-60.

Curran, A. (2012). An investigatory study of the effect of sport participation on aggression, self-esteem, and life satisfaction. Bachelors Thesis, Dublin Business School.

Damian, L.E., Stoeber, J., Negru, O. \& Băban, A. (2013). On the development of perfectionism in adolescence: Perceived parental expectations predict longitudinal increases in socially prescribed perfectionism. Personality and Individual Differences, 55(6), 688-693.

Drake, J. R., Murdock, N. L., Marszalek, J. M. \& Barber, E. (2015). Differentiation of Self-Inventory, Short Form: Development and Preliminary Validation. Journal of Contemporary Family Therapy, 37(2),101-112.

Elliot A. (1999). Approach and avoidance motivation and achievement goals. Journal of Educational Psychologist, 34(3), 169-189.

Entezari, M., Shamsi Pourdehkordi, P. \& Sahaf, R. (2017). The effectiveness of physical activity on cognitive flexibility and perfectionism of the elderly. The elderly, 4, 405-412.

Frost, R.O., Maten, P., Lahar, C.M. \& Rosenblate, R. (1990). The dimensions of perfectionism. Cognitive therapy and research, 14, 449-468.

González, J., Garcés de los Fayos, E. J. \& García Del Castillo, A. (2011). Percepción de bienestar psicológico y fomento de la práctica de activi-dad física en población adolescente. Revista Internacional de Ciencias Socia- les y Humanidades, 21(2), 55-71.

Griban, G., Dzenzeliuk, D., Dikhtiarenko, Z., Yeromenko, E., Lytvynenko, A., Otravenkoa, O., Semeniv, B., Prystynskyi, V. \& Prontenko, K. (2021). Influence of Sambo Wrestling Training on Students' Physical Fitness. Sport Mont, 19(1), 89-95. Doi: 10.26773/smj.210219.

Hadidi, Z., Zare Bahramabadi, M. \& Shafiabadi, A. (2010). The effect of assertiveness education on increasing the differentiation of female high school students in district one of Tehran, Educational Sciences. Educational Research Journal, 6(25), 1-21.

Hamachek, D. E. (1978). Psychodynamics of normal and neurotic perfectionism. Journal of Human Behavior, 15, 27-33.

Hernandez, J.G., Villena, A.J.M. (2019). Perfectionism and sporting practice: Functional stress regulation in adolescence. Anales de psicología / Anales de Psicologia, 35, 148-155. http://dx.doi.org/10.6018/analesps.35.1.1326541

Hill, R. W., Huelsman, T. J., Furr, R. M., Kibler, J., Vicente, B. B., \& Kennedy, C. (2004). A new measure of perfectionism: The Perfectionism Inventory. Journal of personality assessment, 24(1), 20-11.

Hosseinpour, E. \& Kashef, M. M. (2012). Comparison of general health of active and inactive male students in Urmia middle schools. Sport Psychology Studies, 1, 1-6. Doi: 20.1001.1.23452978.1391.1.1.1.3 
Yazd, A.S. Azimkhani, A. \& Aminzadeh, R. (2021). The Effect of sports exercises on students' differentiation and perfectionism. Journal of Sport Sciences Researches, 6(2), 504-520.

Huta, V. \& Ryan, R.M. (2009). Pursuing pleasure versus virtue: The differential and overlapping well-being benefits of hedonic and eudemonic motives. Journal of Happiness Studies, 11, 735-762.

Jamshidi, B., Hossein Chari, M., Haghighat, Sh. \& Razmi, M. R. (2009). Validation of the new scale of perfectionism. Journal of Behavioral Sciences, 3, 35-43.

Khajeh Salehani, M. (2007). The effect of sports activities on reducing depression in blind female students. Exceptional Education, 73, 67-70.

Khalatbari, J., Ghorban Shiroodi, S. \& Hosseini, I. (2011). A Study of the relationship between perfectionism and loneliness with quality of life of medical students in Guilan province. Quarterly Journal of Educational Psychology, 2, 117-131.

Lotfi, M., Mohammadi, J., Sohrabi, M. \& Bagherzadeh, F. (2013). The Comparison of Physical Self-concept between Blind female athletes and Non-athletes. Knowledge and research in applied psychology, 14(4), 45-53.

Mahdavi Nisyani, Z., Ghale noye, F., Fazeli Farsani, F. \& Hashemi, Sh. S. (2016). The effectiveness of exercise on psychological well-being Sleep quality and quality of life of Malayer National University students. World Conference on Psychology and Educational Sciences, Law and Social Sciences at the beginning of the third millennium, Shiraz.

Mohammadpour, F. (2019). Comparison of self-differentiation in female athletes and non-athletes. International Conference on New Horizons in Sports Science and Health, Tehran, New Horizons Science and Technology Association.

Mousavi, S. A, Vaez Mousavi, S. M. K. \& Yaghoubi, H. (2015). The role of sports perfectionism in the dimensions of psychological health and sports success of elite athletes. Sports Psychology Studies, 12, 31-42. Doi: 20.1001.1.23452978.1394.4.12.3.8

Nerland, E. \& Sæther, S. A. (2016). Norwegian football academy players-players self-assessed competence, perfectionism, goal orientations and motivational climate. Sport Mont Journal, 14(2), 7-11.

Olivares, P. R., Cossio-Bolaños, M. A., Gomez-Campos, R., Almonacid-Fierro, A. \& Garcia-Rubio, J. (2015). Influence of parents and physical education teachers in adolescent physical activity. International Journal of Clinical and Health Psychology, 15(2), 113-120.

Pourshahabadi, F. (2015). The effect of sport on socialization and responsibility of individuals. Paper presented at Congress of Pioneers of progress, Tehran, Iran.

Pulido, D., Borràs Rotger, P. A., Salom, M. \& Ponseti Verdaguer, F. J. (2018). Competitive anxiety in grassroots sport in the Balearic Islands. Revista de psicología del deporte, 27(3), 5-9.

Quested, E., \& Duda, J. L. (2009). Perceptions of the motivational climate need satisfaction, and indices of well and ill-being among hip hop dancers. Journal of Dance Medicine \& Science: official publication of the International Association for Dance Medicine \& Science, 13(1), 10-9.

Rao, U.T., Noronha, J.A. \& Adiga, K. (2020). Effect of aerobic exercises on depressive symptoms, anxiety, selfesteem, and quality of life among adults with depression. Clinical Epidemiology and Global Health, 8(4), 1147-1151. https://doi.org/10.1016/j.cegh.2020.04.006

Rasooli, M., Asoudeh, M. H., Tamarchi, F. \& Hosseini, Z. (2016). Investigation of factor structure and validation of Drake and Murdoch self-differentiation questionnaire (short form). Psychometrics, 4(16), 1-10.

Alfermann, D. \& Stoll, O. (2000). Effects of physical exercise morning on self-concept and well-being. International Journal of Sport Psychology, 31, 47-65.

Saatchian, V., Azimkhani, A., Türkmen, M. \& Laein, D. D. (2021). Cycling as transportation \& Covid-19: advantages of shared bicycles during Epidemics. Sport Mont, 19(1), 51-57. Doi: 10.26773/smj.210212

Sahafi, E. S. \& Piri, M. (2020). The effect of a forced aerobic exercise period in adolescence on the negative effects of maternal separation stress on cardiac oxidative stress in adult male rats. Applied Biological Science Studies in Sport, 8, 63-72. 
Salesi, M., Shakur, E., Pouranfar, S., Koushki Jahromi, M. \& Roozbeh, J. (2014). The effect of a period of exercise on stress, anxiety, depression, and hypertension in kidney transplant patients. Jahrom University of Medical Sciences Quarterly, 12, 31-38.

Sarv, M. (2008). The mediating role of test anxiety in the relationship between perfectionism and students' academic achievement. Master Thesis. Shahid Beheshti University.

Shajee, R., Koozehchian, H. Amiri, M. \& Eghbali Hashtjin, F. (2011). Determining the Relationship between Perfectionism and Social Physical Anxiety in Women with Regular Physical Activity. Sports Management, 3, 85-101.

Smith, L.L. \& Elliott, C.H. (2017). Demystifying and defeating depression. Depression for dummies (pp. 9-20). New Jersey, NJ: Wiley.

Sohrabi, R., Asadi, M., Habibollahzade, H. \& PanaAli, A. (2013). Relationship between self-differentiation in Bowen's family therapy and psychological health. Procedia-Social and Behavioral Sciences, 84, 17731775 .

Soltani Shal, R., Mohammadian Sharabaf, H.R. \& Ghanaei Chamanabad, A. (2013). The effectiveness of exercise on general health, sleep quality and quality of life of Ferdowsi University students. Qazvin University of Medical Sciences, 17(69), 40-46.

Springer, Ch., Appleton, P. R. \& Hill, A. P. (2012). Perfectionism and athlete burnout in junior elite athletes: The mediating role of motivation regulations. Journal of Clinical Sport Psychology, 6, 129-45.

Stober, J. \& Damian, LE. (2014). The Clinical Perfectionism Questionnaire. Further evidence for two factors capturing Perfectionism strivings and concern. Personality and Individual Differences, 61-62, 38-42. doi:10.1016/j.paid.2014.01.003.

Stumpf, H. \& Parker, W. D (2000). A hierarchical structural analysis of perfectionism and its relation to other personality characteristics. Personality and Individual Differences, 28, 837-852.

Sufiani, H. (2007). The Relationship between personality dimensions and perfectionism dimensions with general health. Master Thesis. University of Tabriz, Tabriz, Iran.

Tuason. M. T. \& Friedlander M. L. (2000). Do parents' differentiotion levels predict those of their adult children? And other tests of Bowen theory in a Philippine Sample. Journal of Counseling Psychology, 47, 27-35.

ZalBeyki, B., Pakdaman, M., Kurdi, H. \& Ghotbi, M. (2016). The Effect of Nominated Traditional Games on Symptoms Reduction of Attention Deficit/ Hyperactivity Disorder among the Primary School Students . Knowledge \& Research in Applied Psychology, 17(4), 85-94.

Zoghi, L., Torab, B. \& Ajilchi, B. (2019). The Relationship between Differentiation of Self and Social Anxiety with the Mediating Role of Mindfulness in Obese Women. Biquarterly Iranian Journal of Health Psychology, 2(1), 115-124.

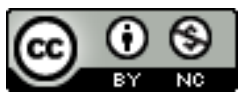

Except where otherwise noted, this paper is licensed under a Creative Commons Attribution 4.0 International license. 